\title{
Clinical Burden of C-Reactive Protein/Albumin Ratio Before Curative Surgery for Patients with Gastric Cancer
}

\author{
YUJI TOIYAMA, TADANOBU SHIMURA, HIROMI YASUDA, HIROYUKI FUJIKAWA, YOSHIKI OKITA, \\ MINAKO KOBAYASHI, MASAKI OHI, SHIGEYUKI YOSHIYAMA, JYUNICHIRO HIRO, \\ TOSHIMITSU ARAKI, YASUHIRO INOUE, YASUHIKO MOHRI and MASATO KUSUNOKI \\ Department of Gastrointestinal and Pediatric Surgery, Division of Reparative Medicine, \\ Institute of Life Sciences, Graduate School of Medicine, Mie University, Mie, Japan
}

\begin{abstract}
To assess the relationship of $C$-reactive protein/albumin ratio $(C A R)$ to outcomes and surgical site infection (SSI) in gastric cancer (GC) treated with curative intent, we retrospectively assessed 384 patients with GC for CAR, SSIs, disease-free survival (DFS), overall survival (OS) and other factors. We found SSIs in 42 patients (10.9\%). Pathological T-stage, TNM classification, body mass index, duration of surgery, blood loss and preoperative CAR were significantly associated with SSIs; in multivariate analyses, CAR [hazard ratio $(H R)=2.98, p=0.003$ ] and duration of surgery $(H R=2.34, p=0.029)$ independently predicted SSI. Age, sex, $T$-and $N$-stages, tumor size and serum carcinoembryonic antigen (CEA) were associated with high CAR, and high CAR, CEA and CA19-9 combined was associated with shorter OS ( $p=0.0001)$ and DFS $(p=0.0001)$. Multivariate analyses also linked high CAR to early recurrence $(H R=2.21, p=0.011)$ and poor prognosis $(H R=1.82, p=0.038)$. We show, for the first time to our knowledge, that a high CAR predicts SSI, early recurrence and poor prognosis in patients with GC treated with curative intent.
\end{abstract}

Gastric cancer (GC) accounts for about $8 \%$ of all cancers and $10 \%$ of cancer-related deaths (1). Although the survival benefit of surgical treatment for GC is recognized, related prognostic predictive factors are inadequate, and should be improved, as they affect treatment decision-making (2).

Surgical site infections (SSIs) are a leading cause of nosocomial infectious complications, accounting for $14-16 \%$

\footnotetext{
Correspondence to: Yuji Toiyama, Department of Gastrointestinal and Pediatric Surgery, Division of Reparative Medicine, Institute of Life Sciences, Graduate School of Medicine, Mie University, Mie 514-8507, Japan. Tel: +81 592315294, Fax: +81 592326968, e-mail: ytoi0725@clin.medic.mie-u.ac.jp
}

Key Words: Gastric cancer, CRP/albumin ratio, recurrence. prognosis, surgical site infection. of nosocomial infections overall and $38 \%$ of nosocomial infections among surgical patients (3). SSIs after radical gastrectomy for GC are a clinically important issue as they are associated with prolonged hospitalization, increased treatment costs, decreased patient quality of life (3-5), and increased mortality.

Systemic inflammatory response has been associated with poor outcomes for many cancer types (6). Several inflammation-based oncological prognostic systems have been developed in the past decade $(7,8)$, including the Glasgow Prognostic Score (GPS) (9). The GPS is based on two simple components: serum levels of C-reactive protein (CRP) and albumin, which have their own cutoff values, and allow GPS to divide patients with cancer into three independent groups before surgery (10).

A high ratio of CRP to albumin (CAR), is correlated with poor outcomes in patients with acute medical admissions and sepsis $(11,12)$. CAR is quantitative, with a continuous value range, and is reportedly a good predictor of outcomes for patients with hepatocellular carcinoma (13), colorectal cancer (14) and esophageal squamous cell carcinoma (15). However, its clinical impact in GC has not been addressed.

This retrospective study evaluated the influence of CAR on short-term postoperative outcomes, especially SSI. We also investigated associations between CAR and clinicopathological findings, including overall (OS) and disease-free (DFS) survival in patients with GC treated with intention-to-cure (ITC).

\section{Patients and Methods}

Patients. Data for 384 patients who had undergone ITC surgery for GC (stages I-III) at the Department of Gastrointestinal and Pediatric Surgery of Mie University Graduate School of Medicine from January 2001 to December 2011 were included in this retrospective study. Staging was performed according to the Japanese Classification of Gastric Carcinoma (16). The type of surgical resection (i.e. distal subtotal gastrectomy, proximal subtotal gastrectomy, or total gastrectomy) and extent of lymph-node 
dissection were also selected according to the Japanese gastric cancer treatment guidelines (16). Curative resection was defined as the absence of any residual tumor in the surgical bed, with a margin that was pathologically negative for tumor invasion. No patient received chemotherapy or radiotherapy before ITC surgery and none suffered perioperative mortality.

SSIs include incisional SSIs and organ/space SSIs, and were classified according to the criteria of the Centers for Disease Control and Prevention (3). Incisional SSIs included wound infections, as demonstrated by the presence of purulent fluid or pus in the wound incision. Hyperemia and local warming at the surgical site were also accepted as criteria for incisional SSIs. Organ/space SSIs included anastomotic leakage and intra-abdominal abscesses, defined as the presence of septic fluid in the peritoneal space proven by surgical drainage or needle aspiration and bacteriological culture. Postoperative anastomotic leakage was diagnosed using contrast radiography.

All patients received prophylactic first-generation cephalosporin antibiotics (cefazolin) for 1 day, according to Japanese guidelines on hospital-acquired infection; $1.0 \mathrm{~g}$ of cefazolin being administered by an anesthesiologist. Infusions were started soon after induction of anesthesia to ensure achievement of peak blood levels of antibiotics during surgery. Further doses of antibiotics were given every $3 \mathrm{~h}$ during the operation.

Patients were followed-up using our standard protocol every $12-$ 16 weeks for at least 1 year. This protocol included tumor-marker studies, computed tomography, endoscopically examinations, ultrasonography, and chest radiography. Bone scans were performed when bone metastasis was indicated. Data collected from inpatient and outpatient records included demographic data (age and sex), tumor-specific data (pathological data including $\mathrm{T}$ classification, lymph-node metastasis, tumor differentiation, lymphatic and venous ductal invasion), tumor markers [carcinoembryonic antigen (CEA) and carbohydrate antigen 19-9 (CA19-9)] at diagnosis, and survival data (DFS) and OS. Peripheral blood data were collected from patients prior to surgery, and included CRP and albumin level for calculating the CAR.

Cut-off values were $5 \mathrm{ng} / \mathrm{ml}$ for CEA; and $37 \mathrm{U} / \mathrm{ml}$ for CA19-9, according to normal ranges used at our hospital. Blood collection and subsequent analyses were approved by the Institutional Review Boards of Mie University Hospital in Japan (no. 2215). The study was conducted in accordance with the guidelines of the 1975 Declaration of Helsinki. The need for informed consent was waived because of the retrospective nature of the study.

Statistical analysis. The data are presented as means \pm standard deviation (SD). Comparisons were made using the Mann-Whitney test. Correlations were analyzed by Spearman's coefficient analysis. The optimal cutoff thresholds of CAR for SSI prediction and prognosis were obtained by Youden's index. In brief, the optimal cutoff threshold values were determined at the point on the receiver operating characteristic curve at which Youden's index (sensitivity + specificity -1 ) was maximal. Survival curves were based on the Kaplan-Meier product-limit method; comparisons were made using the log-rank test. Prognostic factors were examined by univariate and multivariate analyses (Cox proportional hazards regression model). Risk factors for SSIs were examined by univariate and multivariate analyses (logistic regression model). All $p$-values were two-sided; a value of $p<0.05$ was considered significant. All statistical analyses were carried out using Medcalc 7.2 for Windows (Mariakerke, Belgium).

\section{Results}

Patient characteristics. The study group included 264 men and 120 women, with a median age of 67 years (range $=32-88$ years). Their average body mass index (BMI) was $22.34 \pm 3.45 \mathrm{~kg} / \mathrm{m}^{2}$. Of the 384 registered patients with GC, 178 (46.3\%) underwent open gastrectomy and $206(53.7 \%)$ laparoscopic procedures. Total gastrectomies were performed in 111 patients $(28.9 \%)$, distal gastrectomies in 217 patients (56.5\%), proximal gastrectomies in 27 patients $(7.0 \%)$, and partial gastrectomies in $29(7.6 \%)$. Roux-en-Y reconstructions were performed in 244 (63.6\%), Billroth I in 119 (31.0\%), Billroth II in 14 (3.6\%), and other reconstructions in seven $(1.8 \%)$. According to the Japanese Classification of Gastric Carcinoma, 244 (63.6\%) had stage I disease, 68 (17.7\%) stage II and $72(18.7 \%)$ stage III disease. The median tumor size of registered patients was $30 \mathrm{~mm}$ (range $=4-150 \mathrm{~mm}$ ); median duration of surgery was $307 \mathrm{~min}$ (103-780 min), median blood loss was $260 \mathrm{ml}$ (7-2,311 ml), and median number of dissected lymph nodes per patient was 26 (0-77). The median follow-up time was 47.6 months [95\% confidence interval $(\mathrm{CI})=40.1-54.1$ months $)$.

Association between clinicopathological findings and postoperative SSIs. Postoperative SSIs occurred in 42 patients $(10.9 \%)$ but were not significantly associated with age, sex, American Society of Anesthesiologists classification, procedure (including laparotomy vs. laparoscopy), or reconstruction of intestinal continuity (Table I). However, they were significantly associated with longer duration of surgery $(p=0.033)$, more blood loss $(p=0.030)$, higher BMI $(p=0.033)$, advanced pathological T-stage $(p=0.047)$, advanced TNM stage $(p=0.034)$ and higher CAR level $(p=0.024$; Table I).

High CAR levels and long duration of surgery predict postoperative SSI. We performed multivariate analysis on factors identified as significant in Table I to identify factors independently associated with SSI (Table II). We found that a high CAR (>0.058) and lengthy operation (>307 min) were independent predictors of postoperative SSI (CAR: $\mathrm{HR}=2.98 ; 95 \% \mathrm{CI}=1.42-6.22 ; p=0.0036$; and duration of surgery: $\mathrm{HR}=2.34 ; \mathrm{CI}=1.08-5.06 ; p=0.029$; Table II).

Association between preoperative CAR and clinical factors. Table III shows associations between clinical findings and preoperative CAR in ITC patients with GC. CAR was significantly higher in patients older than 67 years, with male sex, and with indicators of tumor progression such as tumors $>30 \mathrm{~mm}$, lymph-node metastasis, poor differentiation and high CEA level.

Associations between preoperative serum markers and early recurrence and poor prognosis. We produced OS and DFS 
Table I. Association between clinicopathological factors and surgical site infections (SSIs) in patients with gastric cancer treated with intentto-cure.

\begin{tabular}{|c|c|c|c|}
\hline Category & SSI(-) & $\operatorname{SSI}(+)$ & $p$-Value \\
\hline \multicolumn{4}{|l|}{ Age } \\
\hline$\leq 67$ Years & 180 & 17 & \multirow[t]{2}{*}{0.18} \\
\hline$>67$ Years & 162 & 25 & \\
\hline \multicolumn{4}{|l|}{ Gender } \\
\hline Male & 233 & 31 & \multirow[t]{2}{*}{0.56} \\
\hline Female & 109 & 11 & \\
\hline \multicolumn{4}{|l|}{ ASA classification } \\
\hline I-II & 323 & 41 & \multirow[t]{2}{*}{0.61} \\
\hline III-IV & 19 & 1 & \\
\hline \multicolumn{4}{|l|}{ Surgery type } \\
\hline Open & 153 & 25 & \multirow[t]{2}{*}{0.09} \\
\hline Laparoscopic & 189 & 17 & \\
\hline \multicolumn{4}{|l|}{ Reconstruction } \\
\hline B 1 & 109 & 10 & \multirow[t]{4}{*}{0.51} \\
\hline B 2 & 12 & 2 & \\
\hline $\mathrm{R}-\mathrm{Y}$ & 214 & 30 & \\
\hline Other & 7 & 0 & \\
\hline \multicolumn{4}{|l|}{ Gastrectomy type } \\
\hline Total & 94 & 17 & \multirow[t]{4}{*}{0.17} \\
\hline Distal & 197 & 20 & \\
\hline Proximal & 23 & 4 & \\
\hline Partial & 28 & 1 & \\
\hline \multicolumn{4}{|l|}{ Duration of surgery } \\
\hline$\leq 307.5(\mathrm{~min})$ & 178 & 14 & \multirow[t]{2}{*}{0.033} \\
\hline$>307.5(\mathrm{~min})$ & 164 & 28 & \\
\hline \multicolumn{4}{|l|}{ Blood loss } \\
\hline$\leq 260(\mathrm{ml})$ & 179 & 14 & \multirow[t]{2}{*}{0.030} \\
\hline$>260(\mathrm{ml})$ & 163 & 28 & \\
\hline \multicolumn{4}{|l|}{ BMI } \\
\hline$\leq 22.2 \mathrm{~kg} / \mathrm{m} 2$ & 178 & 14 & \multirow[t]{2}{*}{0.033} \\
\hline$>22.2 \mathrm{~kg} / \mathrm{m} 2$ & 164 & 28 & \\
\hline \multicolumn{4}{|l|}{ Tumor size } \\
\hline$\leq 30 \mathrm{~mm}$ & 154 & 12 & \multirow[t]{2}{*}{0.061} \\
\hline$>30 \mathrm{~mm}$ & 188 & 30 & \\
\hline Pathological T-stage & & & \\
\hline $\mathrm{T} 1-2$ & 243 & 23 & 0.047 \\
\hline T3-4 & 99 & 19 & \\
\hline Pathological N-stag & & & \\
\hline $\mathrm{N}-$ & 242 & 24 & 0.103 \\
\hline $\mathrm{N}+$ & 100 & 18 & \\
\hline Pathological differe & & & \\
\hline Differentiated & 189 & 21 & 0.629 \\
\hline Undifferentiated & 153 & 21 & \\
\hline TNM classification & & & \\
\hline I & 223 & 21 & 0.034 \\
\hline II & 61 & 7 & \\
\hline III & 58 & 14 & \\
\hline CAR & & & \\
\hline Mean (SD) & $0.15(0.53)$ & $0.26(0.48)$ & 0.024 \\
\hline CEA (ng/ml) & & & \\
\hline Mean (SD) & $6.0(20.2)$ & $26.9(106.0)$ & 0.11 \\
\hline CA19-9 (U/ml) & & & \\
\hline Mean (SD) & $26.6(86.6)$ & $36.3(67.4)$ & 0.41 \\
\hline
\end{tabular}

ASA: American Society of Anesthesiologists; BMI: body mass index; CA19-9: carbohydrate antigen 19-9; CAR: C-reactive protein/albumin ratio; CEA: carcinoembryonic antigen; SSI: surgical site infection.
Table II. Multivariate analyses of risk factors risk for surgical site infection in patients with gastric cancer treated with intent-to-cure.

\begin{tabular}{lccc}
\hline & \multicolumn{3}{c}{ Multivariate analysis } \\
\cline { 2 - 4 } Factor & HR & $95 \%$ CI & $p$-Value \\
\hline CAR $(>0.058 v s . \leq 0.058)$ & 2.98 & 1.42 to 6.22 & 0.0036 \\
$\begin{array}{l}\text { Duration of surgery } \\
(>\text { median } v s . \leq \text { median) }\end{array}$ & 2.34 & 1.08 to 5.06 & 0.029 \\
Blood loss (>median $v s . \leq$ median) & 1.57 & 0.71 to 3.48 & 0.26 \\
BMI $\left(>22.2 v s . \leq 22.2 \mathrm{~kg} / \mathrm{m}^{2}\right)$ & 1.79 & 0.85 to 3.80 & 0.12 \\
Pathological T-stage $(\mathrm{T} 3-4$ vs. T1-2) & 1.04 & 0.35 to 3.07 & 0.93 \\
TNM stage (III $v s$. I-II) & 2.02 & 0.63 to 6.46 & 0.23 \\
\hline
\end{tabular}

Median surgical time: 307 minutes; median blood loss: $60 \mathrm{ml}$. BMI: Body mass index; CAR: C-reactive protein/albumin ratio; CI: confidence interval; HR: hazard ratio.

curves on the bases of presurgical CEA, CA19-9 and CAR values (Figures 1 and 2). Significantly poorer OS was seen for patients with higher CEA $(p=0.017)$, CA19-9 $(p=0.0015)$ and CAR ( $p=0.0001 ;$ log-rank test; Figure 1$)$. Significantly earlier recurrence was seen in patients with elevated CEA $(p=0.015)$, CA19-9 $(p=0.0009)$ and CAR $(p=0.0001$; logrank test; Figure 2).

High CAR is an independent predictor of poor OS. We evaluated which factors available in pre-and postoperative clinical settings could predict survival in ITC patients with GC. Univariate analysis identified age $>67$ years, male sex, lymph-node metastasis, tumor size $>30 \mathrm{~mm}$, CEA $>5 \mathrm{ng} / \mathrm{ml}$, CA19-9 $>37 \mathrm{U} / \mathrm{ml}$ and CAR $>0.051$ as significant predictors of shorter OS (Table IV). Multivariate analysis using a Cox proportional hazards model showed lymph-node metastasis (HR=9.67; 95\% $\mathrm{CI}=4.53-20.63 ; p<0.0001)$ and $\mathrm{CAR}>0.051(\mathrm{HR}=2.21$; $95 \% \mathrm{CI}=1.19-4.11 ; p=0.011)$ were independent predictors of poor prognosis in patients with ITC GC (Table IV).

High CAR is an independent factor in poor DFS. We evaluated which of the available factors could predict postoperative recurrence in ITC patients with GC. Univariate analysis showed that age $>67$ years, male sex, lymph-node metastasis, tumor size $>30 \mathrm{~mm}$, CEA $>5 \mathrm{ng} / \mathrm{ml}$, CA19-9 $>37 \mathrm{U} / \mathrm{ml}$ and CAR $>0.051$ were significantly associated with shorter DFS (Table IV). In multivariate analysis, higher CAR (HR=1.82; 95\% $\mathrm{CI}=1.03-3.23$; $p=0.038)$, lymph node metastasis ( $\mathrm{HR}=9.96 ; 95 \% \mathrm{CI}=4.80$ 20.66; $p<0.0001)$ and larger tumor size $(\mathrm{HR}=2.78$; $95 \%$ $\mathrm{CI}=1.14-6.77 ; p=0.024)$ were independent predictors of early recurrence in ITC GC patients (Table IV). 
Table III. Associations between clinicopathological factors and preoperative serum C-reactive protein/albumin ratio (CAR).

\begin{tabular}{llc}
\hline Categories & Serum CAR (mean \pm SD) & $p$-Value \\
\hline Age & & \\
$\quad \leq 67$ Years & $0.119 \pm 0.526$ & $<0.0001$ \\
$\quad>67$ Years & $0.215 \pm 0.528$ & \\
Gender & $0.195 \pm 0.579$ & 0.006 \\
$\quad$ Male & $0.103 \pm 0.383$ & \\
$\quad$ Female & & \\
Lymph-node metastasis & $0.107 \pm 0.362$ & 0.0018 \\
$\quad$ Absent & $0.306 \pm 0.776$ & \\
$\quad$ Present & & \\
Serosal invasion & $0.105 \pm 0.392$ & $<0.0001$ \\
$\quad$ Absent & $0.310 \pm 0.737$ & \\
$\quad$ Present & & \\
Tumor size & $0.108 \pm 0.393$ & 0.047 \\
$\quad \leq 30 \mathrm{~mm}$ & $0.212 \pm 0.610$ & \\
$>30 \mathrm{~mm}$ & & \\
Histology & $0.162 \pm 0.450$ & 0.05 \\
$\quad$ Well/mod & $0.173 \pm 0.613$ & \\
$\quad$ Other & & \\
Serum CEA & $0.149 \pm 0.498$ & 0.005 \\
$\quad \leq 5 \mathrm{ng} / \mathrm{ml}$ & $0.235 \pm 0.637$ & \\
$>5 \mathrm{ng} / \mathrm{ml}$ & $0.185 \pm 0.56$ & 0.36 \\
Serum CA19-9 & $0.079 \pm 0.085$ & \\
$\quad \leq 37 \mathrm{U} / \mathrm{ml}$ & & \\
$>37 \mathrm{U} / \mathrm{ml}$ & & \\
\hline
\end{tabular}

CA19-9: Carbohydrate antigen 19-9; CEA: carcinoembryonic antigen, Well/mod: well/moderately differentiated, SD: standard deviation.

\section{Discussion}

To our knowledge, this is the first study to demonstrate the clinical implications of preoperative CAR in patients with GC.

Our first finding was that CAR and long surgical duration are independent, significant predictors of SSI occurrence in patients after curative resection of GC.

Next, we found that high CAR was significantly associated with advanced GC status, including lymph-node metastasis, serosal invasion, larger tumor size, poorly differentiated cancer and high levels of CEA, resulting in poor OS and DFS in ITC patients with GC. Furthermore, high CAR is an independent predictor of shorter OS and DFS in these patients. Collectively, preoperative CAR is a novel predictor of both short-term outcomes (postoperative SSIs) and long-term outcomes (recurrence and survival) in patients with GC.

Numerous risk factors have been associated with SSIs after gastrectomy, including advanced age (17), BMI $>25 \mathrm{~kg} / \mathrm{m}^{2}$ (18), male sex (19), open gastrectomy (17), heavy blood loss (4), and long surgical duration $(17,20,21)$. In several largescale surveys, multivariate regression analyses have shown that surgical duration is a significant risk factor for SSIs after gastrointestinal surgery, including gastrectomy (17, 20, 21). Although our univariate analysis also showed that patientrelated (BMI), procedure-related (blood loss and operation duration), tumor-related factors (advanced pathological T- and TNM stage) were significantly associated with SSIs, in multivariate analysis, we found surgical duration was a strong independent risk factor for SSIs. Thus, longer surgery as a result of higher $\mathrm{BMI}$, or greater blood loss as a result of advanced tumor, may be responsible for SSIs.

Interestingly, we also found preoperative high CAR to be another independent risk factor of SSIs in patients with GC. Malnutrition is common among oncology patients; it leads to reduced performance status and quality of life, and is associated with a high risk of postoperative infection (22$24)$. The presence of systemic inflammation, as indicated by a high CRP level and a low albumin level, is associated with weight loss in patients with various solid tumor types (2527). Therefore, both high CRP and low albumin levels (which can equate to high CAR) might be linked to malnutrition followed by postoperative SSIs. Few data are currently available in the literature regarding the effects of systemic preoperative inflammation on the development of postoperative infection. Moyes et al. reported an independent association between systemic inflammation (elevated preoperative white cell count and modified GPS) and postoperative infection following ITC resection for colorectal cancer (28). Mohri et al. also confirmed that systemic preoperative inflammation, as evidenced by GPS, independently predicts postoperative infection in gastrointestinal cancer (24). Thus, these findings support our results that CAR, which is based on CRP and albumin, is an independent risk factor for SSIs in patients after ITC surgery for GC. Therefore, preoperative CAR and long surgical duration should be considered when deciding on continuation of prophylactic antimicrobial agents or use of preoperative intensive therapeutic antimicrobial agents.

Surgical resection is currently the cornerstone strategy for non-metastatic GC. In Asia, particularly in Japan and South Korea, gastrectomy with D2 lymphadenectomy is the standard surgical treatment (16), and Western countries also recommend D2 dissection based on long-term follow-up data (29). However, surgical treatment alone for advanced GC, even complete resection, is associated with high recurrence rates (30). Adjuvant chemotherapy has been shown to improve outcomes for patients with advanced GC who undergo ITC resection (31). S-1 monotherapy is the standard adjuvant chemotherapy for patients with stage II/III GC in Japan (32). However, not all patients benefit from adjuvant chemotherapy and instead only have severe side-effects, either because these patients already have excellent prognoses, or because their tumors do not respond to certain chemotherapeutic agents. Therefore, routine use of the 

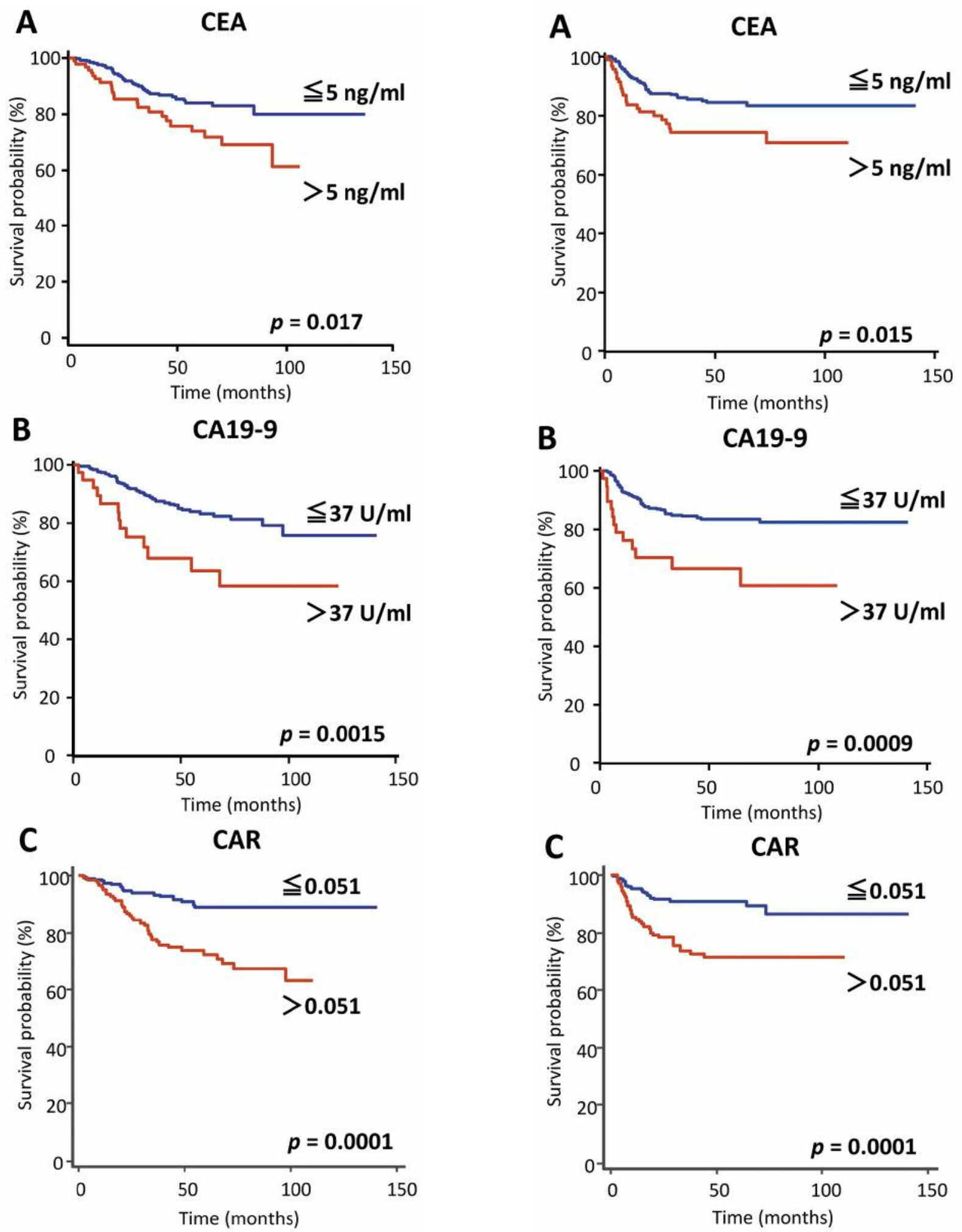

Figure 1. Overall survival (OS) for patients treated for gastric cancer with curative intent (stages I-III) by preoperative serum marker levels, including carcinoembryonic antigen (CEA) $(A)$, carbohydrate antigen (CA) 19-9 (B) and CRP/albumin ratio (CAR) (C). Patients with high CEA, CA19-9 and CAR had significantly worse prognoses.

Figure 2. Disease-free survival (DFS) for patients treated for gastric cancer with curative intent (stages I-III) by preoperative serum marker levels, including carcinoembryonic antigen (CEA) (A), carbohydrate antigen (CA) 19-9 (B) and CRP/albumin ratio $(C A R)(C)$. Patients with high CEA, CA19-9 and CAR had significantly earlier recurrences. 
Table IV. Univariate and multivariate analyses for factors associated with overall (OS) and disease-free (DFS) survival.

\begin{tabular}{|c|c|c|c|c|c|}
\hline & \multirow[b]{2}{*}{ Category } & \multicolumn{2}{|c|}{ Univariate analysis } & \multicolumn{2}{|c|}{ Multivariate analysis } \\
\hline & & HR 95\% CI & $p$-Value & $\mathrm{HR}(95 \% \mathrm{CI})$ & $p$-Value \\
\hline \multicolumn{6}{|l|}{ OS } \\
\hline Age & $>67$ vs. $\leq 67$ Years & $2.21(1.32-3.71)$ & 0.0027 & $1.65(0.93-2.93)$ & 0.08 \\
\hline Gender & $\mathrm{M} v s . \mathrm{F}$ & $2.33(1.21-4.46)$ & 0.01 & $1.32(0.62-2.77)$ & 0.46 \\
\hline Lymph-node metastasis & Present $v s$. Absent & $10.37(5.71-18.85)$ & $<0.0001$ & $9.67(4.53-20.63)$ & $<0.0001$ \\
\hline Tumor size & $>30 v s . \leq 30 \mathrm{~mm}$ & $2.82(1.56-5.12)$ & 0.0006 & $0.76(0.35-1.64)$ & 0.49 \\
\hline Histology & Other $v s$. Well $/$ mod & $0.93(0.56-1.55)$ & 0.8 & & \\
\hline Serum CEA & $>5 v s . \leq 5 \mathrm{ng} / \mathrm{ml}$ & $1.87(1.11-3.15)$ & 0.01 & $1.39(0.78-2.47)$ & 0.25 \\
\hline Serum CA19-9 & $>37$ vs. $\leq 37 \mathrm{U} / \mathrm{ml}$ & $2.60(1.41-4.81)$ & 0.0023 & $1.43(0.73-2.79)$ & 0.29 \\
\hline Serum CAR & $>0.051 v s . \leq 0.051$ & $2.18(1.32-3.61)$ & 0.0023 & $2.21(1.19-4.11)$ & 0.011 \\
\hline \multicolumn{6}{|l|}{ DFS } \\
\hline Age & $>67 v s . \leq 67$ Years & $1.80(1.09-3.00)$ & 0.022 & $1.26(0.73-2.18)$ & 0.39 \\
\hline Gender & $\mathrm{M} v s . \mathrm{F}$ & $2.11(1.12-3.95)$ & 0.02 & $1.11(0.55-2.24)$ & 0.76 \\
\hline Lymph-node metastasis & Present $v s$. Absent & $16.59(8.43-32.63)$ & $<0.0001$ & $9.96(4.80-20.66)$ & $<0.0001$ \\
\hline Tumor size & $>30$ vs. $\leq 30 \mathrm{~mm}$ & $8.17(3.53-18.90)$ & $<0.0001$ & $2.78(1.14-6.77)$ & 0.024 \\
\hline Histology & Other $v s$. Well $/ \mathrm{mod}$ & $1.43(0.87-2.35)$ & 0.15 & & \\
\hline Serum CEA & $>5 v s . \leq 5 \mathrm{ng} / \mathrm{ml}$ & $1.87(1.12-3.14)$ & 0.017 & $1.62(0.94-2.81)$ & 0.08 \\
\hline Serum CA19-9 & $>37$ vs. $\leq 37 \mathrm{U} / \mathrm{ml}$ & $2.70(1.47-4.98)$ & 0.001 & $1.34(0.69-2.57)$ & 0.37 \\
\hline Serum CAR & $>0.051 v s . \leq 0.051$ & $2.74(1.65-4.54)$ & 0.0001 & $1.82(1.03-3.23)$ & 0.038 \\
\hline
\end{tabular}

CA19-9: Carbohydrate antigen 19-9; CAR: C-reactive protein albumin ratio; CEA: carcinoembryonic antigen; CI: confidence interval; HR: hazard ratio; M: male; F: female; Well/mod: well/moderately differentiated.

standard regimen alone cannot be supported. Our study demonstrated that high CAR is an independent indicator of shorter DFS and OS, and of lymph-node metastasis. CAR may help clinicians tailor the best possible adjuvant chemotherapy for each individual patient with ITC GC.

The mechanism by which high CAR affects SSIs, recurrence and survival after ITC resection for GC is unclear. Cancer and inflammation have been shown to have a relationship for which several possible mechanisms have been proposed $(33,34)$. Firstly, tumor growth or invasion can induce tissue inflammation. Secondly, tumor necrosis and hypoxia, or local tissue damage, can activate inflammatory responses. Thirdly, cancer cells and tumorassociated leukocytes can induce production of inflammatory cytokines, such as tumor necrosis factor, interleukin-1, -6, and -8 , and vascular endothelial growth factor. These inflammatory cytokines and chemokines facilitate cancer growth, invasion, metastasis, angiogenesis, subverted host immune response, and resistance to cytotoxic drugs. Elevated levels of CRP, a comprehensive marker of systemic inflammation, was found to predict shorter survival in patients with various cancer types (35-37).

In contrast, albumin is the most abundant serum protein, and the most commonly used marker for nutritional status. It is also useful in predicting the prognoses of patients with several types of cancer (38). Several mechanisms have been proposed to explain the anticancer effects of albumin, including its ability to stabilize cell growth and DNA replication, buffer various biochemical changes, maintain calcium and sex hormone homeostasis to protect against sex hormone-induced cancer, and provide antioxidant effects against carcinogens such as nitrosamine and aflatoxin (39). In addition, malnutrition, which is very common among patients with GC and is reflected by low albumin, can weaken a number of human defense mechanisms, including anatomic barriers, cellular and humoral immunity, and phagocyte function, thus increasing susceptibility to infection and further compromising the response to treatment (40).

Collectively, we believe that nutritional status and the systemic inflammatory response play major roles in SSI occurrence and GC progression after curative surgery. Therefore, CAR is a combination of indicators for these two predictors of adverse outcome, which may further enhance its predictive value. Prospective clinical studies failed to find any benefit for serum albumin supplementation, and its preoperative use for patients with cancer remains controversial. However, some studies have found that improved preoperative nutritional status reduced the length of hospital stay and improve prognosis $(41,42)$. In addition, there are currently several studies investigating the ability of anti-inflammatory therapy (removing activated leukocytes from the peripheral blood by perioperative leukocyte apheresis) in order to prevent postoperative surgical infections in patients with ulcerative colitis $(43,44)$, and to 
extend survival of patients with GC in a recent trial (45). Our findings suggest that both short- and long-term outcomes could be improved in patients after curative surgery for GC by boosting their nutritional status and reducing the inflammatory status. If this is validated in clinical trials, we would recommend preoperative nutritional and antiinflammatory treatments in order to optimize the CAR, and then perform surgery at the optimal time.

We acknowledge several potential limitations to this study. Firstly, it was a retrospective study from a single institution, and with a small sample. However, the surgical procedures (R0 resection plus D2 lymphadenectomy), laboratory examinations, and follow-up were uniform throughout the entire study period. Another limitation is heterogeneity in the patients' post-surgical treatments, especially their adjuvant chemotherapy regimen. Finally, the CAR cut-off value in this study is likely biased because it was selected using receiver operating characteristic analysis. Therefore, independent studies are needed to confirm our results.

In conclusion, we believe this study to be the first to show that both a preoperative high CAR and long surgical duration are independent risk factors for SSI. Moreover, analysis of both preoperative serum markers and postoperative clinicopathological indicators shows CAR to independently affect OS and DFS in patients undergirding ITC surgery for GC. Owing to its simplicity, low price and availability, CAR can be useful in assessing SSI risk and prognosis, and enabling perioperative management to prevent SSIs and GC recurrence.

\section{Conflicts of Interest}

The Authors have no conflicts of interest to disclose.

\section{References}

1 Jemal A, Bray F, Center MM, Ferlay J, Ward E and Forman D: Global cancer statistics. CA Cancer J Clin 61: 69-90, 2011.

2 Van Cutsem E, Dicato M, Geva R, Arber N, Bang Y, Benson A, Cervantes A, Diaz-Rubio E, Ducreux M, Glynne-Jones R, Grothey A, Haller D, Haustermans K, Kerr D, Nordlinger B, Marshall J, Minsky BD, Kang YK, Labianca R, Lordick F, Ohtsu A, Pavlidis N, Roth A, Rougier P, Schmoll HJ, Sobrero A, Tabernero J, Van de Velde C and Zalcberg J: The diagnosis and management of gastric cancer: expert discussion and recommendations from the 12th ESMO/World Congress on Gastrointestinal Cancer, Barcelona, 2010. Ann Oncol 22(Suppl 5): v1-9, 2011.

3 Mangram AJ, Horan TC, Pearson ML, Silver LC and Jarvis WR: Guideline for prevention of surgical site infection, 1999. Hospital Infection Control Practices Advisory Committee. Infect Control Hosp Epidemiol 20: 250-278; quiz 279-280, 1999.

4 Migita K, Takayama T, Matsumoto S, Wakatsuki K, Enomoto K, Tanaka T, Ito M and Nakajima Y: Risk factors for surgical site infections after elective gastrectomy. J Gastrointest Surg 16: 1107-1115, 2012.
5 Tu RH, Huang CM, Lin JX, Chen QY, Zheng CH, Li P, Xie JW, Wang JB, Lu J, Cao LL and Lin M: A scoring system to predict the risk of organ/space surgical site infections after laparoscopic gastrectomy for gastric cancer based on a large-scale retrospective study. Surg Endosc 30: 3026-3034, 2016.

6 Roxburgh CS, McMillan DC: Role of systemic inflammatory response in predicting survival in patients with primary operable cancer. Future Oncol 6: 149-163, 2010.

7 McMillan DC: The systemic inflammation-based Glasgow Prognostic Score: a decade of experience in patients with cancer. Cancer Treat Rev 39: 534-540, 2013.

8 Guthrie GJ, Charles KA, Roxburgh CS, Horgan PG, McMillan DC and Clarke SJ: The systemic inflammation-based neutrophillymphocyte ratio: experience in patients with cancer. Crit Rev Oncol Hematol 88: 218-230, 2013.

9 Forrest LM, McMillan DC, McArdle CS, Angerson WJ and Dunlop DJ: Comparison of an inflammation-based prognostic score (GPS) with performance status (ECOG) in patients receiving platinum-based chemotherapy for inoperable nonsmall-cell lung cancer. Br J Cancer 90: 1704-1706, 2004.

10 Ishizuka M, Nagata H, Takagi K, Horie $\mathrm{T}$ and Kubota K: Inflammation-based prognostic score is a novel predictor of postoperative outcome in patients with colorectal cancer. Ann Surg 246: 1047-1051, 2007.

11 Fairclough E, Cairns E, Hamilton J and Kelly C: Evaluation of a modified early warning system for acute medical admissions and comparison with C-reactive protein/albumin ratio as a predictor of patient outcome. Clin Med (Lond) 9: 30-33, 2009.

12 Ranzani OT, Zampieri FG, Forte DN, Azevedo LC and Park M: C-reactive protein/albumin ratio predicts 90 -day mortality of septic patients. PLoS One 8: e59321, 2013.

13 Kinoshita A, Onoda H, Imai N, Iwaku A, Oishi M, Tanaka K, Fushiya N, Koike K, Nishino $\mathrm{H}$ and Matsushima M: The Creactive protein/albumin ratio, a novel inflammation-based prognostic score, predicts outcomes in patients with hepatocellular carcinoma. Ann Surg Oncol 22: 803-810, 2015.

14 Ishizuka M, Nagata H, Takagi K, Iwasaki Y, Shibuya N and Kubota K: Clinical significance of the C-reactive protein to albumin ratio for survival after surgery for colorectal cancer. Ann Surg Oncol 23: 900-907, 2016.

$15 \mathrm{Xu} \mathrm{XL}, \mathrm{Yu} \mathrm{HQ}, \mathrm{Hu} \mathrm{W}$, Song Q and Mao WM: A novel inflammation-based prognostic score, the C-reactive protein/ albumin ratio predicts the prognosis of patients with operable esophageal squamous cell carcinoma. PLoS One 10: e0138657, 2015.

16 Japanese Gastric Cancer A: Japanese Classification of Gastric Carcinoma: Third English Edition. Gastric Cancer 14: 101-112, 2011.

17 Utsumi M, Shimizu J, Miyamoto A, Umeshita K, Kobayashi T, Monden $\mathrm{M}$ and Makimoto $\mathrm{K}$ : Age as an independent risk factor for surgical site infections in a large gastrointestinal surgery cohort in Japan. J Hosp Infect 75: 183-187, 2010.

18 Ozalp N, Zulfikaroglu B, Gocmen E, Acar A, Ekiz I, Koç M and Tez M: Risk factors for surgical site infection after gastrectomy with D2 lymphadenectomy. Surg Today 39: 10131015, 2009.

19 Smith JK, McPhee JT, Hill JS, Whalen GF, Sullivan ME, Litwin DE, Anderson FA and Tseng JF: National outcomes after gastric resection for neoplasm. Arch Surg 142: 387-393, 2007. 
20 Imai E, Ueda M, Kanao K, Kubota T, Hasegawa H, Omae K and Kitajima M: Surgical site infection risk factors identified by multivariate analysis for patient undergoing laparoscopic, open colon, and gastric surgery. Am J Infect Control 36: 727-731, 2008.

21 Imai E, Ueda M, Kanao K, Miyaki K, Kubota T and Kitajima M: Surgical site infection surveillance after open gastrectomy and risk factors for surgical site infection. J Infect Chemother 11: 141-145, 2005.

22 Tang R, Chen HH, Wang YL, Changchien CR, Chen JS, Hsu $\mathrm{KC}$, Chiang JM and Wang JY: Risk factors for surgical site infection after elective resection of the colon and rectum: a single-center prospective study of 2,809 consecutive patients. Ann Surg 234: 181-189, 2001.

23 Pessaux P, Msika S, Atalla D, Hay JM, Flamant Y; French Association for Surgical Research: Risk factors for postoperative infectious complications in noncolorectal abdominal surgery: a multivariate analysis based on a prospective multicenter study of 4718 patients. Arch Surg 138: 314-324, 2003.

24 Mohri Y, Miki C, Kobayashi M, Okita Y, Inoue M, Uchida K, Tanaka K, Inoue $\mathrm{Y}$ and Kusunoki M: Correlation between preoperative systemic inflammation and postoperative infection in patients with gastrointestinal cancer: a multicenter study. Surg Today 44:859-867, 2014.

25 O'Gorman P, McMillan DC, McArdle CS: Longitudinal study of weight, appetite, performance status, and inflammation in advanced gastrointestinal cancer. Nutr Cancer 35: 127-129, 1999.

26 McMillan DC, Watson WS, O'Gorman P, Preston T, Scott HR and McArdle CS: Albumin concentrations are primarily determined by the body cell mass and the systemic inflammatory response in cancer patients with weight loss. Nutr Cancer 39: 210-213, 2001.

27 O'Gorman P, McMillan DC and McArdle CS: Impact of weight loss, appetite, and the inflammatory response on quality of life in gastrointestinal cancer patients. Nutr Cancer 32: 76-80, 1998.

28 Moyes LH, Leitch EF, McKee RF, Anderson JH, Horgan PG and McMillan DC: Preoperative systemic inflammation predicts postoperative infectious complications in patients undergoing curative resection for colorectal cancer. Br J Cancer 100: 1236$1239,2009$.

29 Okines A, Verheij M, Allum W, Cunningham D, Cervantes A; ESMO Guidelines Working Group: Gastric cancer: ESMO Clinical Practice Guidelines for diagnosis, treatment and followup. Ann Oncol 21(Suppl 5): v50-54, 2010.

30 Yoo CH, Noh SH, Shin DW, Choi SH and Min JS: Recurrence following curative resection for gastric carcinoma. Br J Surg 87: 236-242, 2000.

31 Sun P, Xiang JB, Chen ZY: Meta-analysis of adjuvant chemotherapy after radical surgery for advanced gastric cancer. Br J Surg 96: 26-33, 2009.

32 Sakuramoto S, Sasako M, Yamaguchi T, Kinoshita T, Fujii M, Nashimoto A, Furukawa H, Nakajima T, Ohashi Y, Imamura H, Higashino M, Yamamura Y, Kurita A, Arai K; ACTS-GC Group: Adjuvant chemotherapy for gastric cancer with S-1, an oral fluoropyrimidine. N Engl J Med 357: 1810-1820, 2007.
33 Mantovani A, Allavena P, Sica A and Balkwill F: Cancer-related inflammation. Nature 454: 436-444, 2008.

34 Elinav E, Nowarski R, Thaiss CA, Hu B, Jin C and Flavell RA: Inflammation-induced cancer: crosstalk between tumours, immune cells and microorganisms. Nat Rev Cancer 13: 759-771, 2013.

35 Crumley AB, McMillan DC, McKernan M, McDonald AC and Stuart RC: Evaluation of an inflammation-based prognostic score in patients with inoperable gastro-oesophageal cancer. $\mathrm{Br}$ J Cancer 94: 637-641, 2006.

36 Szkandera J, Stotz M, Absenger G, Stojakovic T, Samonigg H, Kornprat P, Schaberl-Moser R, Alzoughbi W, Lackner C, Ress AL, Seggewies FS, Gerger A, Hoefler G and Pichler M: Validation of C-reactive protein levels as a prognostic indicator for survival in a large cohort of pancreatic cancer patients. $\mathrm{Br} \mathrm{J}$ Cancer 110: 183-188, 2014.

37 Szkandera J, Gerger A, Liegl-Atzwanger B, Absenger G, Stotz M, Samonigg H, Maurer-Ertl W, Stojakovic T, Ploner F, Leithner $\mathrm{A}$ and Pichler M: Validation of the prognostic relevance of plasma C-reactive protein levels in soft-tissue sarcoma patients. Br J Cancer 109: 2316-2322, 2013.

38 Gupta D and Lis CG: Pretreatment serum albumin as a predictor of cancer survival: a systematic review of the epidemiological literature. Nutr J 9: 69, 2010.

39 Seaton K: Albumin concentration controls cancer. J Natl Med Assoc 93: 490-493, 2001.

40 Chandra RK: Nutrition and immunology: from the clinic to cellular biology and back again. Proc Nutr Soc 58: 681-683, 1999.

41 Migita K, Takayama T, Saeki K, Matsumoto S, Wakatsuki K, Enomoto K, Tanaka T, Ito M, Kurumatani N and Nakajima Y: The prognostic nutritional index predicts long-term outcomes of gastric cancer patients independent of tumor stage. Ann Surg Oncol 20: 2647-2654, 2013.

42 Huerta S, Arteaga JR, Sawicki MP, Liu CD and Livingston EH: Assessment of routine elimination of postoperative nasogastric decompression after Roux-en-Y gastric bypass. Surgery 132: 844-848, 2002.

43 Miki C, Okita Y, Yoshiyama S, Araki T, Uchida K and Kusunoki M: Early postoperative application of extracorporeal leukocyte apheresis in ulcerative colitis patients: results of a pilot trial to prevent postoperative septic complications. J Gastroenterol 42: 508-509, 2007.

44 Itabashi M, Ikeuchi H, Araki T, Kono T, Nakamura T, Takesue Y, Kameoka S and Kusunoki M: Effectiveness of leukocytapheresis in suppressing the occurrence of surgical site infections following surgery for ulcerative colitis. Surg Today 38: 609-617, 2008.

45 Rothwell PM, Fowkes FG, Belch JF, Ogawa H, Warlow CP and Meade TW: Effect of daily aspirin on long-term risk of death due to cancer: analysis of individual patient data from randomised trials. Lancet 377: 31-41, 2011.

Received September 30, 2016

Revised October 13, 2016

Accepted October 14, 2016 